May 2020

\title{
Collection Development Challenges in Slavic \& East European Libraries: A Literature Review
}

Sebastian C. Galbo

SUNY University at Buffalo, scgalbo@buffalo.edu

Follow this and additional works at: https://scholarworks.sjsu.edu/ischoolsrj

Part of the Collection Development and Management Commons, Scholarly Communication Commons, and the Slavic Languages and Societies Commons

Acknowledgements

Many thanks to Valerie Nesset, MLIS, PhD, Associate Professor, UBIT Faculty Fellow, Department of Information Science (University at Buffalo)

\section{Recommended Citation}

Galbo, S. C. (2020). Collection Development Challenges in Slavic \& East European Libraries: A Literature Review. School of Information Student Research Journal, 10(1). https://doi.org/10.31979/ 2575-2499.100104 Retrieved from https://scholarworks.sjsu.edu/ischoolsrj/vol10/iss1/4

This article is brought to you by the open access Journals at SJSU ScholarWorks. It has been accepted for inclusion in School of Information Student Research Journal by an authorized administrator of SJSU ScholarWorks. For more information, please contact scholarworks@sjsu.edu. 


\title{
Collection Development Challenges in Slavic \& East European Libraries: A Literature Review
}

\author{
Abstract \\ The purpose of this paper (a literature review) is threefold. First, it seeks to understand the current \\ landscape of collection development practices within the contexts of academic Slavic and Eastern \\ Europe (SEE) collections. Second, this paper aims to grasp the challenges that impact how librarians \\ devise collection development policies for academic SEE holdings. Third, by drawing on current field \\ research, it investigates how SEE collections are addressing these challenges and sustaining user \\ services. It asks, for example, what tools/resources SEE collections employ to remain vital, relevant, and \\ accessible. Based on these three foci, this paper provides an assessment of the library and information \\ science field's major challenges, and examines various indications of what the future holds for academic \\ SEE collections and their user populations.
}

\section{Acknowledgements}

Many thanks to Valerie Nesset, MLIS, PhD, Associate Professor, UBIT Faculty Fellow, Department of Information Science (University at Buffalo)

\section{About Author}

Sebastian C. Galbo is currently completing his MLIS at SUNY University at Buffalo. He holds a BA in English (Niagara University) and an MA in liberal/cultural studies (Dartmouth College). 
While there are numerous perennial challenges facing Slavic librarianship today, among the foremost challenges are the "erosion of bibliographic control, the disappearance of established vendors, inadequate acquisitions budgets, and ineffective exchange programs" (Trehub, 2009, p.172). Admittedly, these are issues that vex many subspecialty library collections, even the most trafficked and well-funded holdings of academic libraries. On a deeper level, however, perhaps the most intractable challenge is a growing indifference and "erosion of confidence in the traditional mission of the humanities and the value of a liberalarts education" (Trehub, 2009, p.173). Indeed, niche academic disciplines, such as Slavic studies, would seem to be among the first to undergo erosion. Like other disciplines of the humanities, "there is little that Slavic librarians can do to forestall the feared decline of area and language studies or the humanities in general" (Trehub, 2009, p.181). This is not so much a sigh of resignation as it is a realistic stance toward acknowledging the shifting needs, attitudes, and user preferences of student patrons with different research habits-however, much opportunity exists for Slavic librarians who wish to preserve the relevancy and rich legacy of their collections for future generations of users.

In light of these aforementioned challenges, the purpose of this paper is threefold. First, it seeks to understand the current landscape of collection development policies within the contexts of academic Slavic and Eastern Europe (SEE) collections - that is, what are the internal and external institutional factors that presently influence how SEE collection development policies are written? Second, this paper aims to grasp the challenges that impact how librarians devise collection development policies for academic SEE holdings. At the outset of this research, there seems to be countless factors that loomed intimidatingly over development efforts, especially within the contexts of SEE collections. What first comes to mind are the immediate conveniences of Google and comparably easyto-use search engines; language translation software/applications; and the now entrenched user demand for digitally accessible content. Thus, with the everrising costs of providing access to expensive academic publications, what collection development practices are SEE librarians employing to maintain user access to these resources? Third, by drawing on current field research, this paper investigates how SEE collections are addressing these challenges and sustaining user services. It asks, for example, what tools/resources are SEE collections employing to remain vital, relevant, and accessible? Based on these three foci, this paper provides a comprehensive assessment of the library and information science (LIS) field's major challenges; indications of what the future holds for academic SEE collections and their user populations; and some reflections on how future SEE collection development policies might be improved and nuanced.

This paper concludes by providing a proposed methodology for preparing informed and up-to-date collection development policies for SEE holdings. For example, the implementation of an organized interview process with SEE librarians of different academic institutions. Interviewees would be queried and prompted to discuss the present challenges facing SEE libraries and how their respective institutions are managing issues and user needs. In this way, collection development, though highly individual based on each library's holdings, would be 
a somewhat untied collaborative effort in which SEE librarians are in constant communication with one another about how to keep their collections relevant and resilient.

\section{Historical Overview}

This section presents a historical overview of SEE collections. By examining the specific history of the Library of Congress's SEE collections, this section provides general background information on how these collections came to occupy shelf space in the national library. Placing the literature review within a larger historical context provides a more informed understanding of the roles and objectives SEE collections have played throughout the development of the American academic library. Second, this review surveys American scholarship, published between 1995-2018, to articulate a current understanding of the various challenges that SEE collections face. The third section examines the resolutions, tools, and resources SEE librarians employ to address and manage these challenges.

\section{Slavic/East European Collections in the American Library: A General History}

To understand the historical development of SEE collections, it is useful to examine the evolution of Slavic material acquisition at the Library of Congress (the LC), which was slow to develop into a mature and comprehensive process over the span of a century. The history of SEE collections, specifically Russian materials, in the United States began in 1800, when the LC was founded. \$5,000 was budgeted to purchase 155 titles (spanning 728 volumes) and three maps. All materials, aside from one, were published in English. The express purpose of acquiring Slavic materials was to provide content for congressmen engaged in writing legislation, so the major collected genres during this period included history, law, and geography. Interestingly, the exclusion of foreign language materials was bolstered by Thomas Jefferson who, in a missive to the chair of the Library Committee of Congress, stated that no titles in other languages were to be admitted. Books concerning Russia grew incrementally, but the most reasonable explanation for the small stature of the collection was likely due to the fact there was no Russian population in America at that time. Based on historical record, the LC's collection development policy, though not formalized exactly the way today's policies are, dictated that no foreign language titles were to be acquired (Cannon, 2014).

During the tumult of the War of 1812, British forces burned down the LC in 1814. Jefferson sold his personal library, which included 6,487 volumes worth $\$ 23,950$, in an effort to restore the LC. Interestingly, Jefferson's library contained three Russian-language titles, three French-language titles published in Russia, and 14 English-language titles published about Russia (Cannon, 2014). Historians acknowledge that Jefferson could not read Russian, but that these volumes were given to Jefferson by American diplomats and civil servants who worked abroad, as well as political contacts who furnished books as gifts.

By 1849, the LC's catalog evidenced a nascent but growing collection of

Russian-language texts; however, the dominant trend of acquiring mainly 
translations or titles concerning Russian-related subjects remained entrenched (Cannon, 2014). Of course, the major impetus that drove early collection development at the LC was how funds were to be allocated. Institutional quarrelling broached the foundational question that would eventually dictate the LC's collection development philosophy (and whether it would ever prioritize the acquisition of foreign language materials): Would the LC serve only congressmen or the larger American public? This question prompted much internal cacophony concerning the scope and mission of the library. A positive turning point for the LC's foreign language holdings came in 1836, when Count Dmitrii Petrovich Buturlin, a Russian nobleman who died in Italy, offered to sell his library to the LC. The so-called Buturlin collection, which included 25,000 titles and 200 manuscripts in Italian, Greek, and Latin, was purchased. Ironically, the Count's library contained not a single Russian-language work, though its subsequent acquisition by the LC prompted librarians to continue disputing whether the LC should employ a strict collection policy aligned with the research needs of congressmen or widen its scope to become a national library (Cannon, 2014).

The first decade of the twentieth century registered the most significant institutional changes within the LC's leadership and acquisitions ideology. The long-time debate concerning whether the LC would be a parochial collection for congressmen or serve as a national library, open to the public, coalesced in the paradigm-shifting decision to hire a new library director. This director envisioned building the LC into a national library, an internationally recognized bastion of American learning and research. To build this democratic collection, the LC's leadership sought, in part, to retain educated staff with knowledge of foreignlanguage materials. In 1902, Alexis Babine was hired to expand the LC's international holdings. Babine is credited with successfully negotiating two historic purchases that would permanently establish the LC's Slavic collection. First, in 1904, the LC purchased the Martin Hattala Library, which held 1,500 volumes of classic works on Slavic literature and linguistics; it also contained Slavic periodicals and pamphlets (Cannon, 2014). Two years later, in 1906, Babine orchestrated the monumental purchase of the 80,000-volume Yudin Collection. The purchase of the Yudin Collection is lauded by historians as a total shattering of 'tradition and parochial practice' that spurred the growth of the LC's foreign-language materials (Cannon, 2014, p. 51). Indeed, the acquisition of the Yudin Collection aligned perfectly with the philosophy of the library's new leadership - that the LC was to grow into an open and ever-growing entity, not a resource reserved for elite politicians.

Generally, the period spanning from 1918 to 1939 is regarded as the 'golden age' of academic SEE language libraries in the United States (Ference, 2006). Despite the U.S Congress-imposed immigration quotas during the 1920s, the Slavic population that settled in the United States prior to the First World War established flourishing insular ethnic communities wherein small publishing houses, parishes, fraternal organizations, schools, and libraries were founded. One major Slavic community, the Slovaks (who ranked the second most populous immigrant community after the Polish) established fraternal organizations and social clubs that functioned to preserve traditional customs and the written/spoken 
language (Ference, 2006). Thus, libraries were the cynosure of these ethnic communities, as they provided a space for study, serious discussion, and the preservation of Slavic languages. Noting the existence of these particular libraries is important because it demonstrates that the LC was not the only place that amassed Slavic-language content; instead, Slavic materials existed peripherally, too, in academic and ethnic collections.

For the purpose of brevity, this section will conclude at this point on the timeline of SEE library evolution. It is important to note, however, that the LC's collection development policy often served as the model that academic libraries would emulate. Following the end of the Second World War and as the United States moved into the latter half of the twentieth century, interest in Russian materials (and Slavic media in general) grew astronomically and became priority acquisitions.

\section{SEE Library Collection Development: Challenges \& Issues}

SEE academic collections are vital parts of library holdings at American institutions of higher learning. SEE materials are especially critical at institutions that maintain specialty humanities disciplines that focus on Slavic Studies, East European, and other area/foreign-language specializations. Area studies collections serve as the institutional spine of the international programs of many American colleges and universities (Schaffner \& Baird, 2003). It is perhaps no surprise, however, that despite the importance of these niche collections, that foreign-language materials have a low-use status in North American libraries (Giullian, J. \& Monroe-Gulick, 2017). Usage rate is often the benchmark used to assess the overall vitality and worth of a particular collection, but low-use status is not an issue/stigma that can be easily reversed.

Indeed, there is a correlative, and understandable, fear between low-usage material and available funding for those resources - after all, why should library budgets allot funds for material that is rarely used? To answer this question, research that focuses on SEE collection development concentrates not so much on how to increase usage of SEE materials; rather, it aims to evaluate the reasons why low-use foreign language materials deserve continued acquisition and funding (Giullian, J. \& Monroe-Gulick, 2017). A recent study spearheaded by Kansas University's International Collections librarians conducted a Faculty, Researcher, and Graduate Student Needs Assessment Survey, the purpose of which was to collect data that represented the research needs of area studies students and faculty. On a positive note, the survey results reported that $91 \%$ of responders emphasized the high importance of collections and content; $67 \%$ emphasized the importance of research guides and discovery tools; and 37\% responded that access to an information management provider (Slavic Studies librarians) was also of high importance (Giullian, J. \& Monroe-Gulick, 2017). As this research demonstrates, low-usage rates do not provide wholly representative evidence of a particular collection's overall worth. Furthermore, as library content is increasingly digitized and services are offered through web-based systems, the ability to 'privilege' the acquisition of only high-usage materials has grown tenuous (Atkinson, 2006). Even if a collection is not accessed as frequently as 
English-language materials, area studies collections still serve user populations in need of their resources and the professionals who steward them.

By extension, a related challenge that continues to vex SEE collection librarians, especially those who work in high-specialty area studies, is the dilemma of developing a foreign-language collection that is culturally rich and interesting but decidedly unneeded by the vast majority of users. This is an uncommon, but unresolved, challenge for SEE collection development professionals who must weigh the intrinsic worth, but considerable expense, of building a collection of obscure foreign-language materials that will likely receive little usage. Recent scholarship considers the development of a collection that would house vernacular-language material from the North Caucasus, specifically Turkic tongues such as Kumyk, Karachai-Balkar, and Nogai (Condell, 2017). SEE librarians who promote such collections believe, with infinite sanguinity, that if a collection of obscure language were to be established, researchers would eventually come (this date unknown) to use it (Condell, 2017). These librarians, such as those based at the International \& Area Studies Library of University of Illinois at Urbana-Champaign, debate whether obscure materials have immediate value to justify acquisition investments. This camp of librarians warns that SEE collections that do not contain hard-to-obtain foreign-language materials risk becoming linguistically impoverished and simplified collections (Condell, 2017). Furthermore, SEE librarians in favor of collecting Turkic-language material (and other little-known tongues) argue that without access to this information, future scholars will lose opportunities to study cultures that would otherwise enrich related academic subjects, such as politics, history, gender studies, and literature - that is, what could be lost, what might be missed if this material is not accessible to future scholars? (Condell, 2017). Contrasting viewpoints, however, are understandable, as this type of obscure material is not only challenging to find and acquire, but rather expensive to purchase and difficult to catalogue.

\section{Underused SEE Collections}

Low-usage status is a problem for collection development policy because SEE librarians must also contend with competing technological and digital contenders that complicate the acquisition of library materials. For example, if Slavic Studies librarians know that students prefer digital journal resources, they may not develop an acquisitions policy that promotes only the obtainment of hardcopy monographs. Such major technological and digital contenders may seem obvious but are worth identifying for the purposes of understanding how SEE collection development policy is impacted today. The first major challenge is understanding the changing information behavior of user populations (Wallach, 2009). A salient and well-known preference of many younger users is the use of Google to begin research, which underscores that many patrons are not regarding libraries as the starting point of academic inquiry. Additionally, students are not spending as much time in libraries, let alone consulting bibliographic resources for locating material-instead, students, in general, are expected to spend their time working in a rare manuscript archive, preparing conference papers, and participating in academic and professional societies (Wallach, 2009). 
Indeed, SEE librarians have not confronted these changes with a Luddite unwillingness to evolve with new technological advancements. These changes impact what Slavic Studies librarians called 'Slavic information literacy (SIL)' (Brewer, 2009). Research demonstrates that changes in information literacy have produced critical shortcomings in students' bibliographic capabilities. For example, SEE and area studies students lack an ability to articulate specific and narrow thesis research boundaries; furthermore, students struggle to ideate and identify useful 'keywords' to focus search results (Wallach, 2009, p. 224). Interestingly, a major but often understated reason why SEE students may fail to fully embrace library collections is the dominant culture of higher education. This culture is informed by various economic and financial factors that pressure students to complete their studies as quickly as possible (the allure of postgraduation employment prospects, etc.) (Wallach, 2009). While these particular issues do not necessarily impact SEE collection development policies directly, they do demonstrate major distractions and lacunae in users' information literacy habits, which cause otherwise valuable materials to go overlooked and, therefore, unused.

Compounding these new permutations in students' research habits is a general deterioration of comprehensive bibliographic control, shrinking acquisition budgets, and vanishing material vendors (Trehub, 2009). As alluded to earlier, the proliferation of technological conveniences, such as Google, iPads, and smartphones, has led users to access vast amounts of information outside the confines of the library. This upheaval in technology has altered the means and methods with which people use to think about and access information (Cadmus, 2011). These changes in the library landscape coalesce into a major challenge for libraries.

Aside from the global impacts of major technological changes and the widespread permutation of information literacy, SEE collections also face very immediate and practical challenges. These challenges include the evaluation and preservation of Slavic materials. Echoed throughout SEE library and information science research is the need to preserve at-risk and deteriorating materials. This poses a major collection development challenge as librarians must implement preservation controls if these collections are to acquire rare/older materials in the future. Of course, SEE libraries cannot acquire more material without first taking responsibility and preserving that which they currently hold. Many Slavic collections contain poorly bound materials published on acidic paper (Schaffner $\&$ Baird, 1999). The issue of preservation is pronounced for Slavic collections because much of the material is printed on low-quality acidic paper (very typical of publications printed in East Central Europe and the former Soviet Union). This paper has the brittle consistency of periodical print (Schaffner \& Baird, 1999). Historically, Russia's economic conditions required publishers to use whatever paper materials were readily available; moreover, there was no strong concern in Russia to produce durable print material that would serve to extend the lifespans of resources (Schaffner and Baird, 1999). Lending this issue of preservation statistical weight, a study conducted at the University of Kansas's libraries determined that only $2.26 \%$ of its Polish material is brittle, while $17.43 \%$ of the 
Russian collection is rated as brittle and in need of immediate preservation (Schaffner and Baird, 1999). On a positive note, however, book production in both Poland and Russia has increased the use of acid-free paper. Statistically, since 1991, 29\% of Poland-printed and over 15\% of Russia-printed volumes have been published on acid-free paper (Schaffner and Baird, 1999). These changes in production suggest that material preservation will not be an eternal issue; however, SEE libraries must, in the meantime, devise an affordable and practical methodology for preserving (and digitizing) aging material.

\section{The Diminishing Spaces of SEE Collections}

Among other immediate issues facing SEE library collections include shrinking real estate to house physical materials. Diminishing space to house material impacts collection development because librarians must consider how/where newly acquired material will 'fit' within existing spaces. For example, the Alumni Memorial Library of St. Mary's College in Orchard Lake, Michigan, which acquires rare and out-of-print Polonia, must store its volumes in inaccessible, hard-to-reach areas (Majewski, 2003). Worst of all, due to spatial restrictions, the collection must house its overflow materials in buildings prone to mildew and decay, which threatens to (further) compromise rare material (Majewski, 2003). This may appear to be a mundane issue that not every SEE library faces; however, the larger reality that cannot be ignored is that the library collections that serve area disciplines (such as Slavic, Polish, and Bulgarian Studies) typically operate on the most parsimonious budgets and, therefore, do not have immediate access to larger storage facilities with the necessary climate controls.

Some Polonia and Slavic collections face far trickier and intractable problems, such as institutional obscurity, despite their affiliation with a college or university (Majewski, 2003). Some American SEE collections are 'ethnic institutions,' meaning that there is a certain degree of 'insularity' that delays external networking with other academic institutions (Majewski, 2003). Unfortunately, this lack of exposure results in keeping these valuable materials hidden from scholars and students who would otherwise benefit from access. This challenge can be lessened by establishing connections and interlibrary loan networks with other research institutions; however, this can be a time-consuming and cumbersome effort, and many smaller SEE collections are employed by an already overcommitted staff. Even in the year 2020, despite all myriad digital conveniences and global connectivity, there likely remain SEE collections that are not organized under an accessible and uniform cataloguing system. For example, it was only with a grant issued under the library Services and Construction Act that the aforementioned Polonia collection of St. Mary's College was able to transition to the OCLC System (Majewski, 2003). Again, some SEE collections remain veiled in obscurity due to a lack of trained library personnel and funds required to properly catalogue and digitally promote their holdings to the academic world - in the meantime, these materials risk moldering in inadequate storage units.

\section{Shrinking Budgets \& Vanishing Vendors}


From a collection development standpoint, SEE collections face a large challenge that will most likely never quit harrying academic libraries: budget shortages (Trehub, 2009). Funding limitations fuel increasing pressure to acquire material and provide access to information in the most economic fashion possible. To address the issue, SEE collections have implemented cooperative solutions, such as resource exchange and loan networks, to keep costs at a manageable level. For example, OCLC, the Research Libraries Information Network, and the Center for Research Libraries create consortia that unite collections. Seasoned librarians, though optimistic about the efficacy of 'library cooperation,' such as consortia, doubt that it can ever be a cure-all solution for budget shortages (Schaffner, 1999, p. 263). This cautionary optimism stems from a general worry that large consortia will overlook (or worse, ignore) the specific needs and priorities of smaller, local collections. Moreover, there is concern that librarians may establish redundant cooperative efforts with an aim to 'acquire local control over a project,' which could result in 'scarce resources being spread too thin' (Schaffner, 1999, p. 264). For SEE consortia to be truly efficacious, there are various essential aspects on which participants need to reach concurrence (Boissé, 1995). For the purpose of this paper, it would not be worthwhile to itemize each of these aspects in detail; however, there are some that clearly influence the SEE consortia managed by the University of Kansas. These aspects include: 'Library cooperation is easier to establish in a hitherto unexplored area; The more democratic the organization you create is, the more difficult the decision making; Your library will never be the same; Be prepared to lose some autonomy; Once established, a library cooperative never ceases to exist' (Boissé, 1995, pgs. 90-93). These particular aspects (or what may be understood as compromises/concessions) have proved to be particularly useful during the process of establishing SEE consortia that unite academic collections.

The gradual dwindling of Slavic material vendors also poses an enormous challenge. In April 2008, the Russian Press Service (RPS) closed, which stymied librarians' ability to purchase affordable language material. Although the closing of the RPS now seems like a long-ago misfortune, there has not been a comparable replacement, and the costs of language materials continue to increase (Trehub, 2009). In response, wealthy institutions, such as Yale University, dispatch their SEE librarians to visit East European countries to establish approval plans and material exchange programs with in-country vendors, such as those based in Estonia, Bosnia, and Latvia (Lorković, 2009). These acquisition trips serve to establish exchange programs with in-country academic and national libraries. Of course, such an arrangement is ideal for library collections whose acquisition efforts are flagging due to the high costs of material; unfortunately, though, due to the expense and luxury of such travel opportunities, it is hardly a feasible option for most budget-strangled institutions. Examples of global acquisition expeditions, however, do lend some insight into how fruitful international relationships might be established remotely (Lorković, 2009). For example, approval plans and catalogs can be exchanged to emphasize areas of collections that can be strengthened and diversified. Although this is an attractive 
way to facilitate collection development, it is difficult to execute remotely-and, unignorably, it will remain an option that only elite libraries can afford.

Regarding SEE collection approval plans, recent library and information science research indicates that these plans are not necessarily indispensable keys to building comprehensive collections. In fact, professionals admonish that 'exclusive reliance on them contribute to a limited and homogenous collection' (Dali \& Dilevko, 2005, p. 238). Therefore, to circumvent some acquisition limitations, some SEE libraries resort to alternative methods of obtaining new material. To illustrate this point, recent SEE library research has demonstrated that although many academic libraries have formal approval plans in place to develop their collections, many opt to use 'non-approval-plan-based (NAPB)' collecting practices. These practices, as evidenced by research, serve to facilitate the acquisition of so-called 'grey literature'; that is, materials that fall outside of mainstream content, such as texts from remote areas and those sold by small/alternative publishing houses (Dali \& Dilevko, 2005). This is an especially interesting emerging trend because, until the disintegration of communist governments, exchange programs were among the few reliable methods of obtaining SEE-language content.

Research, facilitated through a web-accessible questionnaire, surveyed the acquisition practices of 33 North American libraries and concluded that only six (6) libraries maintain exchange programs (Dali \& Dilevko, 2005). This research also notes that $51.4 \%$ of surveyed libraries adhere to no approval plans; rather, they use an assortment of NAPB methods (Dali \& Dilevko, 2005). To emphasize the significance of this change, it is worth quoting the comment of one questionnaire responder, who writes of Slavic material exchange programs unfavorably: 'We used to send books on exchange (back in the 1960s and 1970s). We sent our [university press] catalogues to our exchange partners and asked them to choose books of equal value to the ones they were supplying us. This was very labor intensive and required good record keeping. We felt we were in fact working for the libraries in [Eastern Europe]' (Dali \& Dilevko, 2005, p. 255). International exchange programs, as a fading practice, are regarded increasingly as a method with considerably high labor costs (Hogg, 2002). As a fresh alternative, NAPB practices include a much less formalized processes of acquiring material, such as book fairs, gifts, independent book agents, and North American bookstores that sell foreign-language material (Dali \& Dilevko, 2005). Evidently, SEE librarians are implementing much more flexible acquisition practices that no longer adhere to a strict approval policy. The challenge remains, however, that although there is more latitude in material acquisition methods, the cost of content remains borderline prohibitive.

In summary, many of the challenges are not wholly unique to SEE collections. Indeed, all collections, ranging from periodicals to rare manuscripts, face similarly pressing issues, such as budget shortages, preservation needs, and even weak (or lack of) consortium-like partnerships that reduce acquisition duplications and related expenditures. Importantly, these challenges are much more pronounced in collections that support area studies, as the libraries that serve these disciplines are smaller and generally considered to less important due 
to low-usage rates. Table 1 below provides a succinct overview of the major challenges facing SEE collections and articulates the far-reaching implications of these challenges.

\section{Table 1. Major Challenges Facing SEE Collection Access, Usage, and Development}

\begin{tabular}{l} 
Challenge \\
Restrictive Budgets \\
Preservation Urgencies \\
Acquisition Expenses \\
Institutional Insularity \\
Spatial Constraints \\
$\begin{array}{l}\text { Changing User Habits / } \\
\text { Information Literacy }\end{array}$ \\
$\begin{array}{l}\text { Perceptions of 'Low- } \\
\text { User Preferences for New } \\
\text { \& Emerging Technologies } \\
\text { Panguage }\end{array}$ \\
\hline
\end{tabular}

Ramifications

- Staff shortages; reduced acquisitions; reduced purchase power; cheaper solutions to issues (material preservation insufficiencies)

- Brittle materials at risk to deteriorate; brittle bindings; limits user usage/mobility due to concerns about fragile condition; impacts feasibility of exchange/interlibrary loan programs

- Limits acquisition of physical/digital resources; impacts faculty and student resource purchase requests; strains future development of collections and potential user engagement

- Limits external awareness of collection; reduces publicity and opportunities to establish collaborative networks/consortia

- Forces smaller collections to house material within inadequate storage spaces (mildew, mold, humidity); poses organizational inconsistencies; complicates future acquisitions/collection expansion

- Curtails need/use of libraries' resources; weakens and oversimplifies research habits; creates gap between library professionals and students; reduces student fluency in bibliographic tools and resources

- Creates gap between library resources and user-preferred tools; impacts how users find, access, and consume information; users do not regard library tools as viable options

- Places a low-priority status on area studies/SEE collections from funding and development standpoints; creates viewpoints that lowusage materials deserve less attention and investment

- Potential curtailment of future scholarship/research opportunities; SEE collection is not comprehensive; risks content homogeneity and simplification; lack of 'obscure' material stifles potential user curiosity

\section{Managing \& Resolving SEE Collection Development Challenges}

This section presents research that proposes tools, methods, and resources that are currently employed by American SEE librarians to manage the previously described collection development challenges. That is, what measures are taken to ensure that these challenges do not compromise collection development efforts? Additionally, this section considers recent research that describes various new bibliographic controls and information literary instruction models that are implemented to serve student users. In doing so, it draws a connection between SEE collection development and how student users access and engage with SEE materials in meaningful ways.

\section{(Re)Connecting Users with SEE Resources}

As stated earlier, SEE collections remain underused, in part, because today's students have information literacy habits that involve consulting major Internet search engines, such as Google, instead of using libraries as springboards for 
initializing research. SEE librarians are aware of how information literacy habits have changed over time and, fortunately, employ practical ways to educate users how to find and access the information they need. For example, some SEE libraries promote the implementation of a simple, one-hour information literacy class that instructs student users how to navigate a library's main homepage, including JSTOR, ArtSTOR, ProQuest, and other digital bibliographic catalogs (Wallach, 2009). Although this type of instruction is by no means unique to SEE studies, it is especially important in light of the interdisciplinary nature of Slavic Studies - that is, it encompasses (and often overlaps with) many disciplines, such as history, art, literature, politics, and geography. The implementation of a onehour class also gives SEE libraries an opportunity to address the resources available through Google Scholar, Google Books, and Google Images as an extension of the scholarly process. The importance of situating these Google sites within the context of information literacy is to discuss how to use precise keywords to conduct focused research-indeed, these skills are even more important in the world of Google because of the vast amount of information offered through its various search engines. Lecturers then end these instructional sessions by reiterating the value of SEE libraries, which serves to remind students that Google is not the only conduit through which information can be obtained (Wallach, 2009). Research also indicates the importance of information literary seminars that instruct students how to use bibliographic resources, such as OCLC WorldCat and Open WorldCat, to conduct advanced searches. These search tools help students to perform precise searches for highly specific content without relying on Google exclusively (Husic, 2017). This type of information literacy instruction is fundamental to SEE collection development because it ensures that users are equipped with the knowledge required to fully benefit from what libraries have to offer.

To reiterate, the ever-increasing expense of purchasing foreign-language material remains a formidable challenge for SEE libraries. Rising costs, however, do not necessarily ring the death knell for SEE collections; in fact, current library and information science research demonstrates that there are many digitization projects and electronic consortia that serve to relieve the financial burden of acquisition budgets. For example, the University of Kansas library used a U.S. Department of Education Title VI Foreign Information Access (TICFIA) grant to launch a digital database containing 60 federal and regional bibliographic catalogues of Russian archives. In collaboration with Rosarkhiv, the federal Russian agency that manages the country's archives, the library used the $\$ 255,000$ grant to develop a database that now enables users to search the contents of 80,000 different archival collections (Schaffner, 2007). This project, known as the Russian Archives Database, provides a user-friendly format that allows students and faculty to search the collections of Russian archives. Before launching this project, some catalogs were inaccessible to users outside of Russia; however, since establishing this database, SEE students and researchers are able to search guides that provide a comprehensive listing of all archival content (Schaffner, 2007). This important project provides access to rare Slavic materials that have been either closed off or unavailable to academics and the general 
public outside of Russian. The holdings of many of these Russian archives have remained hitherto unknown because there has not been an organized dissemination of their catalogs and, furthermore, many are limited to serving only the needs of scholars.

These types of archives also exist in the United States and could benefit from the digital representation of their catalogs. Consider, for example, the Sackner Archive of Concrete and Visual Poetry based in Miami, Florida, which opens its collection only to those who schedule visits (Klähn, 2015). The Sackner Archive houses rare modernist texts, samizdat, and émigré publications, as well as conceptual art, created by Russian, Ukrainian, Czech, Polish, Serbian, and Hungarian writers and artists. This type of archive would benefit significantly if it were to upload a digital copy of its catalog. Skeptical librarians may conclude that although this program was successful in digitally merging the catalogs of thousands of Russian and American SEE archives, it does not lead to acquiring cheaper foreign-language materials. This is certainly true; however, the success of this program demonstrates that it is possible to use federal or state funds to develop a large-scale electronic resource that enhances the accessibility of hardto-find materials (Schaffner, pg. 83). Another fortuitous byproduct of this project has been the subsequent participation of Russian archives that refused to relinquish copyrights at the outset of the project. Since observing how this project has secured the international visibility of other participating archives, these collections have now joined and uploaded their catalogs/holdings to the database (Schaffner, 2007). Although a project of this ambition and magnitude may not be feasible for every SEE library, there are opportunities to develop digitization projects that promote the longevity and richness of foreign-language collections.

These types of collaborative programs beam optimism onto the future of SEE libraries. Research continues to demonstrate that indexing, abstracting, and digitizing catalogs and bibliographies enhances exchange programs and resource sharing among institutions. Open-access catalog sharing platforms, such as the Co-operative Online Bibliographic System \& Services (COBISS), Matarka29, and bilioteka, all work to help users find and access foreign-language resources from Slavic and East European countries (Lenkart, 2016). New Slavic bibliographic portals (used to archive conference proceedings and abstracts), such as Uridicheskaia Rossiia: federal'nyi pravovoi (Russian Federation) and ESM (Ekonomika-Sociologiia-Menedzhment): federal'nyi obrazovatel'-nyi, serve to enhance the visibility and accessibility of Slavic materials. Another fortuitous outcome of international digitization/catalog sharing efforts has been the development of interlibrary loan programs, as well the establishment of virtual SEE scholar communities (Lenkart, 2016). These virtual communities work together to sustain digitization projects, in addition to exchanging ideas and tools for SEE collection development.

\section{Resource Sharing \& Other Tools of Collaboration}

Another tool that SEE librarians employ to curtail material acquisition costs is the "2CUL Slavic" resource-sharing program. Established by Columbia University Libraries and Cornell University Library in 2009, the 2CUL Slavic project merges and coordinates the resource-sharing efforts of these two major university 
campuses. The primary objective of the 2CUL Slavic initiative is to build a crossinstitutional relationship that allows the libraries to leverage the exchange of their collections in order to better manage the increasing costs of foreign-language materials (Davis, 2017). 2CUL Slavic "makes more materials available and accessible to the scholarly community by reducing the number of duplicate titles between the two institutions to a bare minimum" (Davis, 2017, p. 70). Eliminating duplicates by sharing materials effectively diminishes acquisition expenses. Each participating institution collects expensive language material that is of great importance to students and research faculty. Columbia University's collection holds Mongolian, Turkmen, Georgian, Armenian, and other little-collected foreign-language materials. Historically, Cornell collects fewer languages, but still provides many expensive materials in Belarusian, Bosnian, Bulgarian, Croatian, Czech, Hungarian, Macedonian, Polish, Romanian, Russian, Serbian, Slovene, and Slovak (Davis, 2017). Statistical evidence demonstrates that the 2CUL Slavic arrangement is not some impossible-to-implement collection development pipedream-amazingly, a November 2015 catalog search for monographic Russian texts (2011-2015) reported that Columbia had 9,021 volumes, while Cornell had 6,441. Of their combined total of 15,462 volumes, only 279 (less than 2\%) were duplicates. Strikingly, if users had conducted the same search in 2006-2010, predating the establishment of 2CUL Slavic, that duplication rate escalated to 12\% (Davis, 2017). Research also notes that the 2CUL Slavic model has inspired other institutions, such as Princeton University and the New York Public Library, to develop similar resource-sharing programs between their respective SEE collections (Davis, 2017). The success of these models is undoubtedly the future of area studies collections that must contend with the ever-escalating costs of materials. By extension, the 2CUL Slavic example emphasizes that SEE libraries cannot afford to be insular entities - that if they want to remain relevant and solvent resources for users, they must adopt an outlook of collaboration and flexibility.

A SEE librarian based at the University of Illinois at Urbana-Champaign, in Urbana, Illinois, notes that "The future growth of online research resources from Eastern and Southern Europe, Eurasia, and the Baltic region depends on renewed efforts to explore the intellectual production of these regions" (Lenkart, 2016, p. 224). Indeed, SEE librarians struggle to stay abreast of the many new foreign-language materials that are published annually. Research demonstrates that there are many open-access resources that SEE librarians can use to identify what these new materials are and where they can be purchased (Pendse, 2016). Various web-based tools, such as open-access resources, are being used to track and monitor new materials that may be acquired for Slavic collections. For example, SEE librarians at the University of California, Berkeley, compile lists of literary webpages to track new developments and publications in the Czech literary world. The webpages provide links to digital repositories of contemporary, Medieval, and early Czech literature. Moreover, the information provided on these webpages gives SEE librarians an understanding of the current trends in Czech book trade/industry (Pendse, 2016). SEE librarians at Berkeley consult the utility of different Czech webpages based on the following helpful 
criteria: (1) content relevance; (2) content accessibility; (3) content selection; (4) content validity; and (5) helpful links to relevant information (Pendse, 2016, p. 287). These webpages, some of which are bilingual (that is, also written in English) provide valuable information for SEE collection development librarians that would otherwise be very difficult (if not impossible) to find in Englishlanguage publications.

This valuable information includes nominated and winning texts of national Czech book awards; details/bibliographies on contemporary Czech writers; book industry commentary; databases devoted to Czech poetry; book reviews; and news/media about upcoming publications (Pendse, 2016). The evident downside to these types of resources is the language barrier. Of course, librarians can use one of many Internet-based translation services to quickly interpret these webpages. This approach to development resembles the previously mentioned non-approval-plan-based (NAPB) collecting practices (Dali, 2005). By using foreign webpages to search for materials that fall outside the mainstream, SEE librarians can broaden their understanding of the international book market, as well as widen their acquisitions net. There is a firm consensus in the SEE community that the following factors, itemized in Table $\mathbf{2}$ below, are vital to preserving the future of foreign-language collections:

Table 2. Tools \& Resources to Enhance SEE Collection Access, Usage, and Development

Tools / Processes

Multi-institutional collaboration

(i.e., exchange programs, digitization and interlibrary loan)

Engagement with foreign-language resources

Big-and-small collection partnerships (i.e., digital catalog archives, digitization of catalogs)

Current information literacy curricula

\section{Benefits}

- Saves money by reducing the purchase of duplicate materials; potentially increases usage rates; surplus funds from savings can be used to purchase rare materials or allocated for preservation purposes; also increases the pool size of SEE material; opens up collections to a larger user population, therefore heightening usage

- Stay apprised of international book industries, markets, trends, and developments; not relied exclusively on limited English-language vendors to provide up-to-date information on new materials; provides a more informed and sophisticated understanding of foreign book markets

- Mitigates insularity; increases awareness of and accessibility to previously shuttered/underused collections; potential stimulation of scholarly interests/research; establishes a virtual community of SEE librarians/researches; potential acquisition/collection development savings through material-exchange programs

- Ensures users/students understand the range of bibliographic resources available to support research; combats trends/habits in information literacy that default to Google tools; heightens awareness of a library's resources and offerings; establishes connections among librarians, users, students, and faculty; instills advanced search skills

\section{Collection Development Methodologies: Considerations for Future Policies}

This section briefly examines three methodologies/tools that could be used to strengthen collection development efforts: (1) A material acquisitions outlook that is informed by flexible but focused non-approval-plan-based (NAPB) practices; (2) a questionnaire/survey tool to gauge users' material needs, as well as the 
dominant opinions and professional outlooks of SEE librarians; and (3) establishing a collaborative, multi-institutional initiative to curtail acquisition expenditures.

The first major consideration of academic SEE collection development policy is inculcating an acquisitions outlook that is comprehensive but selective. While this may sound cliché, SEE library research focuses extensively on what materials to, rather than not, collect. It may seem perfectly axiomatic not to collect materials that one's user population does not need; however, current research does not examine how collection selection or 'weeding' is performed, or, how SEE collections restrict acquisitions based on user needs. In fact, current research leaves readers with a strong impression that SEE collections, given their focus on niche materials, regard all Slavic content of collectable value. Indeed, little research proposes the ways that SEE libraries can build collections without becoming overly homogenous or unfocused. As presented in this paper, there is a growing trend in SEE collection development for librarians to use NAPB collecting practices to obtain new materials. Although this informal type of approach inspires a more flexible acquisition method, it could also lead to the development of an unfocused collection. SEE collection development policies need to establish an acquisition practice that is focused but inclusive of materials offered outside of mainstream vendor channels. By extension, SEE collection policies also need to establish rigorous weeding protocols, especially for libraries that accept public donations and gifts.

As referenced in the literature review, the Polonia collection that experiences storage issues might mitigate the problem if weeding protocols were in instituted. Admittedly, this is a difficult, and likely dreaded, activity for collections with obscure and/or rare materials; however, without careful selection and removal of content, collections risk impinging on the future acquisition of materials that users may eventually need. Just because something is Slavic does not mean that it must be unquestionably collected, catalogued, and available to users. As stated previously, NAPB practices have potential shortcomings, such as unfocused acquisitions, but they do add an interesting perspective to collection development. Another way SEE libraries can build relevant and resilient collections is by obtaining materials from vendors outside of approval plans. SEE development policies should encourage librarians to find materials because, as already stated, approval plans risk homogenizing and/or narrowing the scope of a collection. NAPB practices can be effective if they are focused on obtaining materials that users need. Different and interesting materials can be found through untraditional conduits, such as independent publishers, off-the-beaten-path tradeshows, or even self-published content - the challenge, however, is encouraging NAPB approaches that concentrate on user needs. By extension, collection development policies can be written to encourage the use of foreignlanguage webpages and resources that provide up-to-date information on literary news, authors, recent scholarship, and bibliographic data. Based on current research, SEE libraries, despite their niche positions, have enormous potential to benefit from a global network of interconnected resources and ideas for collection development. That is, not every academic library, such as the engineering or 
medical sciences, can engage on such a broadly international scale. It is important that SEE collection development policies prioritize different types of international engagement with other libraries, archives, and web-based communities.

Some practical ways to implement or begin thinking about collection weeding include soliciting a questionnaire or survey among a collection's most frequent faculty/student users. The questionnaire would pose simple questions about the perceived low- and high-usage materials; types of materials that responders would like to be collected; and what content is considered outdated or of little importance. This type of questionnaire/survey could achieve a more upto-date, sophisticated understanding of what users need, how collections can remove unwanted material, as well as strengthen ties among libraries, faculty, and students. Another type of questionnaire/survey that might be especially useful to SEE development professionals is one that probes how other SEE librarians build and maintain their libraries. The following questions/prompts, in Table 3 below, might be considered to guide librarians' responses:

\begin{tabular}{|c|c|}
\hline \multicolumn{2}{|c|}{ Questions / Prompts } \\
\hline 1 & $\begin{array}{l}\text { Please identify the major resources, both material and digital, comprising your institution's } \\
\text { Slavic and Eastern European collection. }\end{array}$ \\
\hline 2 & $\begin{array}{l}\text { st popular materials within your collection. Who are the primary users } \\
\text { als? }\end{array}$ \\
\hline 3 & $\begin{array}{l}\text { What are some of the foremost challenges/institutional difficulties facing Slavic and Eastern } \\
\text { European collection development today? How is your collection working to overcome } \\
\text { these challenges? }\end{array}$ \\
\hline 4 & $\begin{array}{l}\text { How does your institution facilitate the development of its current collection holdings? That } \\
\text { is, does your institution issue a user questionnaire to gauge patron needs? How does it } \\
\text { communicate with faculty and student users to determine areas of the collection that require } \\
\text { attention or new materials? }\end{array}$ \\
\hline 5 & $\begin{array}{l}\text { What about your current collection development policy would you revise, change, or update } \\
\text { based on your observations of patron needs? How frequently is your } \\
\text { institution's development policy updated? }\end{array}$ \\
\hline 6 & $\begin{array}{l}\text { For academic libraries working to establish and/or expand its current Slavic and Eastern } \\
\text { European collections, what are among the important factors to consider? }\end{array}$ \\
\hline 7 & $\begin{array}{l}\text { How closely does the Slavic and Eastern European collection collaborate with the } \\
\text { institution's academic faculty, students, and other library departments? Why is this } \\
\text { collaboration important? Are there areas of this collaboration that could use improvement } \\
\text { and/or emphasis? How does this influence collection development? }\end{array}$ \\
\hline 8 & $\begin{array}{l}\text { How does the Slavic and Eastern European collection engage virtual users? How is the } \\
\text { collection development policy written to address the needs of remote users? }\end{array}$ \\
\hline 9 & How is the Slavic and Eastern European collection perceived amongst its constituents? \\
\hline 10 & $\begin{array}{l}\text { ver impinged on improving the } \\
\text { cy been reconceptualized to adapt } \\
\text { ly? }\end{array}$ \\
\hline
\end{tabular}

Using the answers to these questions might provide valuable insight into how other SEE collections are currently developed and maintained by librarians. These types of questions are purposefully broad, so as to ensure that responses are as open-ended and detailed as possible. Most importantly, however, understanding how other SEE libraries function might also serve to identify potential opportunities for material-sharing initiatives or digitization efforts. 
Another methodology that might be implemented to strengthen SEE collection development is, as mentioned before, a fully integrated, multiinstitutional collaboration to reduce acquisition expenditures. The major benefit of this type of collaboration, especially in reference to the 2CUL Slavic initiative, is the gradual elimination of duplicate materials (and, of course, the associated cost savings). The examples cited in this review are gargantuan initiatives and it would be somewhat naïve to assume that all SEE collections can overcome their individual difficulties by simply pooling resources and establishing interlibrary loan programs. The important takeaway from these major institutional successes is that collaborative efforts, whether large or small, are always worthwhile. Consider again, for example, the aforementioned digitization of Russian archive catalogs. Although this effort evolved into a much larger project, it established, for the first time, a network of connected institutions that now benefit from sharing their respective catalog information. What it overcame, most importantly, was the self-sustained insularity of individual collections, thus introducing them to a larger world of potential users.

\section{Conclusion}

Although SEE collections remain confronted by many daunting challenges, current research demonstrates that librarians are using effective tools to keep their collections relevant and resilient. As expressed in some scholarship, a major underlying anxiety is institutional decay, that SEE libraries will succumb to the steady erosion of low-usage rates and a flagging enthusiasm for the humanities. Indeed, abundant warnings in higher education grimly intimate that area studies and other marginal disciplines will be among the first academic strongholds to fade if this enthusiasm continues to diminish. Fortunately, current library research indicates that SEE collections can survive and thrive not by winning large grants or securing massive budgets, but by embracing opportunities for creative partnership. Imperative to success is collaboration. As the above review demonstrates, research also articulates a concern that SEE and other area studies libraries must continue to evolve alongside developing technologies, diverse user needs, and evolving information literacy habits. Research is generally optimistic that SEE libraries can avoid extinction if they build collections and library support systems that meet the current day needs of users. While SEE libraries and others of their ilk may not be able to reverse wilting interest in the humanities, they can position themselves as valuable and purposeful collections that serve an important, if small, user population. 


\section{References}

Atkinson, R. (2006). Six key challenges for the future of collection development. Library Resources Technical Services, 50(4), 244-251.

Boissé, J. (1995). Library cooperation: A remedy but not a panacea. IFLA Journal, 21(2), 89-93.

Brewer, M. and Zitser, E. (2009). Slavic information literacy: Past, present, and future. Slavic \& East European Information Resources, 10(2-3), 117-124.

Cadmus, F. (2011). Things in common: Challenges of the $19^{\text {th }}$ and $21^{\text {st }}$ century librarians. The Green Bag: An Entertaining Journal of Law, 14, 193-209.

Cannon, A. (2014). The origins of the Russian collection at the Library of Congress (18001906). Slavic \& East European Information Resources, 15(1-2), 3-59.

Condill, K. (2017). The idea of the comprehensive research collection, the perils of "Linguistic Impoverishment," and print publications in the Turkic languages of the North Caucasus, 1806-2017 (Part I). Slavic \& East European Information Resources, 18(3-4), 128-151.

Dali, K. and Dilevko, J. (2005). Beyond approval plans: Methods of selection and acquisition of books in Slavic and East European languages in North American libraries. Library, Collections, Acquisitions, \& Technical Services, 29(3), 238-269.

Davis, R. (2017). 2CUL Slavic: The view so far. Slavic \& East European Information Resources, 18(1-2), 67-73.

Dickinson, J. (2017). Knowing nearby others: Approaches to precise terminology in new Slavic vocabularies. IFLA WLIC Paper Annals. Retrieved from http://library.ifla.org/1615/1/098-dickinson-en.pdf

El-Sherbini, M. (2002). Outsourcing of Slavic cataloguing at the Ohio State University libraries: Evaluation and cost analysis. Library Management, 23(6-7), 325-329.

Ference, G. (2006). The Slavic diaspora library: The Slovak-American example. In Gregory Ference and Bradley Schaffner (Eds), Books, bibliographies, and pugs (pp. 7385). Bloomington, IN: Slavica.

Giullian, J. and Monroe-Gulick, A. (2017), Assessment of Kansas University's libraries' Slavic \& Eurasian collection: Purpose, process, and potential. Slavic \& East European Information Resources, 18(1-2), 29-66.

Herrick, M. (2018). Russian art books and folios of the Hoover Institution Library \& Archives: Niche collections one hundred years on. Slavic \& East European Information Resources, 19(3-4), 118-125.

Hogg, R. (2002). The death of exchange. Slavic \& East European Information Resources, $3(2-3), 29-43$.

Husic, G. (2017). Using OCLC WorldCat language indexes to quantify Slavic and Eurasian language collections and answer complex bibliographic questions. Slavic \& East European Information Resources, 18(3-4), 109-127.

Johnston, B. (2015, May). Using digital library collections in the classroom. Scholarship, Research, and Creative Work at Bryn Mawr College. Retrieved from https://repository.brynmawr.edu/blended_learning/2018/2018/3/

Klähn, T. (2015). Russian and East European materials at the Sackner archive of concrete and visual poetry. Slavic \& East European Information Resources, 16(4), 222-228.

Lenkart, J. (2016). Current trends in research resources from Russia, Eastern Europe, and Eurasia: Implications for reference services and resource sharing. Slavic \& East European Information Resources, 17(4), 215-225. 
Pendse, L. (2016). Analyzing the contemporary Czech literary web. Slavic \& East European Information Resources, 17(4), 285-297.

Lorković, T. (2009). Acquisitions trip to the three Baltic states: Estonia, Latvia, and Lithuania, June 3-June 14, 2009. Slavic \& East European Information Resources, 10(4), 332-349.

Majewski, K. (2003). The Polish book collection, Alumni Memorial Library, St. Mary’s College. Polish American Studies, 60(1) (2003), 45-50.

Neubert, M. (2008). "Books.Google.RU”-Google's mass digitization of Russian-language books. Slavic \& East European Information Resources, 9(1), 53-62.

Pendese, L. (2016). Bulgarian print collection at UC Berkeley Library: Using the Bulgarian web resources as collection development tools. WESS Newsletter, 40(1). Retrieved from https://escholarship.org/uc/item/00t285xs.

Schaffner, B. (1999). Specialized cooperative efforts in collection development: An analysis of three Slavic programs. Collection Management, 24(3-4), 263-280.

Schaffner, B. and Baird, B. (1999). Into the dustbin of history? The evaluation and preservation of Slavic materials. College \& Research Libraries, 60(2), 144-151.

Schaffner, B. (2007). A public/private partnership for digitization: The Russian archives database project. Slavic \& East European Information Resources, 8(4), 77-85.

Trehub, A. (2009). Slavic studies and Slavic librarianship revisited: Notes of a former Slavic librarian. Slavic \& East European Information Resources, 10(2-3), 170-184.

Wallach, Ruth. (2009). From Google Books to library catalogs: A consumerist exploration of information literacy for graduate students in Slavic studies. Slavic \& East European Information Resources, 10(2-3), 221-234. 